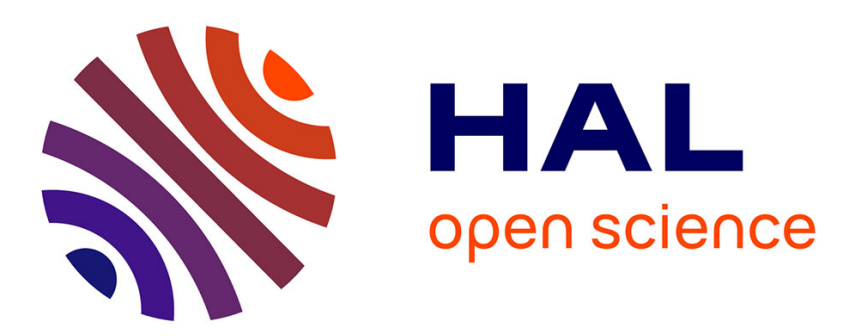

\title{
Requirement engineering of a Cooperative Information System using viewpoints
}

Kahina Kessi, Mourad Oussalah, Zaia Alimazighi

\section{To cite this version:}

Kahina Kessi, Mourad Oussalah, Zaia Alimazighi. Requirement engineering of a Cooperative Information System using viewpoints. IWAISE 2014 (The 3rd International Workshop on Advanced Information Systems for Enterprises ), Nov 2014, TUNIS-TUNISIE, Tunisia. hal-01075556

\section{HAL Id: hal-01075556 https://hal.science/hal-01075556}

Submitted on 18 Oct 2014

HAL is a multi-disciplinary open access archive for the deposit and dissemination of scientific research documents, whether they are published or not. The documents may come from teaching and research institutions in France or abroad, or from public or private research centers.
L'archive ouverte pluridisciplinaire HAL, est destinée au dépôt et à la diffusion de documents scientifiques de niveau recherche, publiés ou non, émanant des établissements d'enseignement et de recherche français ou étrangers, des laboratoires publics ou privés. 


\section{Requirement engineering of a Cooperative Information System using viewpoints}

\author{
Kahina Kessi \\ USTHB University \\ LSI laboratory \\ Algeria \\ kkessi@usthb.dz
}

\author{
Mourad Oussalah \\ Nantes University \\ LINA Laboratory \\ France \\ mourad.oussalah@univ-nantes.fr
}

\author{
Zaia Alimazighi \\ USTHB University \\ LSI laboratory \\ Algeria \\ zalimazighi@usthb.dz
}

\begin{abstract}
In this paper we are interested in cooperative information systems (CIS) in inter-organizational environments. They are information systems on a large scale, which connect different organizations, often autonomous, sharing common goals, forming in this case inter-organizational system (IOS). In order to develop a CIS, we propose a VpCIs approach, which incorporates a notion of software engineering, which are the viewpoints from the needs analysis phase to describe their requirements and needs. This approach defines a meta-model of viewpoint, which enable us to instantiate the viewpoints necessary to identify the needs and requirements of a CIS.
\end{abstract}

Keywords: viewpoints, needs analysis, requirements engineering, cooperative information system.

\section{Introduction}

In a context of globalization of markets, companies of today face many challenges posed by: increased competition, the exceptional growth of services they must offer to their customers, the increased need to provide better quality of service and the necessity of cooperation and collaboration with other business partners to stay competitive in their activity domain and operating in socio-economic environments characterized by dynamism and increased turbulence. Thus, a company can no longer be content with a closed information system, which would cause it to be unable to exchange information with its collaborators and partners. The Cooperative Information System (CIS) area allows supporting the inter-company relations in order to improve interactions and communication between partners. An IOIS itself being a CIS [2], defines an inter-organizational information system as a system that has a special function to support processes that cross borders of an organization. In[2], they explain that a central entity will manage a collaborative process by organizing the intervention of part- ners. In [12], the authors recognize that enterprise interoperability passes through the interoperability of their information systems to improve overall efficiency of a collaborative network. Indeed, behavior, reactivity and dynamics of the company are based largely on the information system through the processes it supports, the applications it offers and data it manages [20]. Size and complexity of these cooperative information systems is therefore growing, their complexity makes their design more difficult. It is so very important to understand the needs and requirements of the system, which leads us to be interested at the first phase of development of a CIS, i.e. the system analysis phase. What we want is to propose an approach which solves the problems related to the development of a CIS in order to propose a tool which let to support this approach using a notion of software engineering: the viewpoints. This article is organized as follow. In the second part we present our motivations and our interest regarding the proposal for an approach oriented viewpoint to the needs analysis phase of CIS. In the third part we present some methods that have addressed the same problem, before moving on to the fourth part where we present our VpCIs approach. Finally we conclude with our perspectives.

\section{Motivation}

The size and complexity of these cooperative information systems is therefore growing, their complexity makes their design more difficult. It is so very important to understand the needs and requirements of the system, which leads us to interest and define the first step of development of a CIS, ie the step of Requirements Engineering (RE). RE is the basis phase of the life cycle development of every project, defining what the stakeholders (users, customers, suppliers, developers, businesses ) in a potential new system need from it, and also what the system must do in order to satisfy that need [9]. We need to find a set of requirements that reflect the needs of these stakeholders. Despite the obvious need for an appropriate level of structure and 
rigor, this critical, complex, and potentially expensive activity in the majority of cases is performed in an ad-hoc manner without a defined process or methodology. The lack of systematic methods with situational process guidance, and experience reports that can easily be applied to real-world situations are serious reasons for the current gap between requirements elicitation and needs analysis in research and practice. [6]. The methods that exist in the domain of RE in software engineering does not allow to address the complex needs of a CIS which involves the cooperation of many stakeholders in a common purpose and each with their own viewpoint. The use of existing approaches based on concepts of: goal, scenario or viewpoint have shown their limits, and work has been done for their integration into a single approach. [15] for example, proposed an approach named CREWS for requirements elicitation in which the authors use both goal and scenario, [3] proposed an approach inspired from CREWS where they integrated goal, scenario and viewpoints. there is also for example the methods VORD or VOSE which used the viewpoints for the requirement engineering. But these methods have not highlighted the concepts of actors, team (group of actors), activity, actions and interactions between actors that must be in a cooperative information systems. For the analysis needs phase of a cooperative information system other factors should be considered. It will be necessary to determine who does what, on what, when, after what and before what, we must define the systems actors and relations or actions and activities that may exist between them. Which implies the intervention of different stakeholders (the expert, designer of CIS, domain user ...) involving several levels of modeling and multiple domains (generic domain (CIS), business application ...). We will try to solve these problems by proposing an approach that highlights these concepts using viewpoints with 5 dimensions in order to have a tool that allows to have a common formalism for each concept and remedy this complexity. This will allow us to decompose the needs of a CIS according to viewpoints of each stakeholder. A viewpoint-based approach to requirements engineering recognizes that all information about the system requirements cannot be discovered by considering the system from a single perspective. Rather, we need to collect and organize requirements from a number of different viewpoints. A viewpoint is an encapsulation of partial information about a systems requirements. Information from different viewpoints must be integrated to form the final system specification [18]. There is several viewpoints methods in RE like : SADT [16],[14], CORE [13], VOSE [8], [11], VORD [10], [17], [7], PreView [19], ISO/IEC/IEEE 42010 standard [1]. In addition, the main arguments in favor of an approach based on viewpoints in requirements engineering are:

- Systems usage is heterogeneous there is no such thing as a typical user. Viewpoints may organize system requirements from different classes of system end-user and other system stakeholders.

- Different types of information are needed to specify systems including information about the application domain, information about the systems environment and engineering information about the systems development. Viewpoints may be used to collect and classify this information.

- Viewpoints may be used as a means of structuring the process of requirements elicitation. [18]

The viewpoint establishes the conventions for constructing, interpreting and analyzing the view to address concerns framed by that viewpoint. Viewpoint conventions can include languages, notations, model kinds, design rules, and/or modeling methods, analysis techniques and other operations on views. A viewpoint is a way of looking at systems. [1]

In this approach, we interest to the cooperative information systems, we first propose a meta-model of viewpoint in the modeling level M2 in order to have a common formalism and to after instantiate the necessary viewpoints to describe a CIS in M1 level, we expect thereafter to provide a tool which allows to support this approach.

\section{Related work and comparison}

Several methods have proposed approaches to respond to needs and requirements of systems, we have oriented our choice to tooled methods as we later, want to propose a tool that will support our approach, knowing that we are interested in CIS and viewpoints, we then selected CREWS, Tropos-i* and MAMIE methods which are interested in collaborative work and we choose methods oriented viewpoint: VORD and VOSE. In the analysis needs phase of a cooperative information system we have to find these notions: Actor, team (group of actors), interaction between the actors, activity (set of actions of a group of actors), action of an actor and requirements. we base our comparisons on these criteria.

\subsection{The CREWS method}

The CREWS [15] method (Cooperative Requirements Engineering With Scenario), is developed under the ESPRIT project (European Research Project Reactive) approach. The objective is to find the system requirements by coupling each goal discovered with a scenario that illustrates the behavior of the system to achieve the goal. Once an object has been selected, a scenario is written to it. In this way, the coupling goal-scenario reduces the problem of 
fuzzy goals.

The method has demonstrated its effectiveness in the requirements specification of a cooperative process by highlighting the concept of goal and scenario, the scenario has to make less fuzzy and more realistic goal, any technique that uses scenarios to discover the goals produces only useful purposes. But what we can say about this method is that: - The method does not highlights the actors, group of actors (team) and their descriptions or descriptions of the activities of the system.

- Fragmentation of requirements captured in multiple scenarios makes difficult the assurance of completeness of the requirements specification.

- It also makes difficult to research the different aspects of the same system functionality across multiple scenarios.

- Sometimes non-functional concerns such as security and performance are treated secondarily compared to the central question of functional concerns.

\subsection{The MAMIE method}

MAMIE (from MAcro to MIcro level requirements Elicitation) [3] developed by bendjenna 2010, for the elicitation of requirements of an inter-organizational system. The MAMIE approach is a methodology which aims to guide systemsâ analysts to elicit requirements in an ICIS. It is composed of two phases: the macro level cooperation and the micro level of inter-company co-operation . It consists, initially, to elicit and specify cooperative activities, constraints of co-operation between companies, and the relevant non functional requirements of the future system (the macro level cooperation). Through interviews, questionnaire, documents study or other elicitation techniques, essential requirements are obtained. In the second phase (the micro level of inter-company co-operation), they try to get requirements necessary to set up goals with constraints identified in the first phase. [4] The method drew inspiration from the CREWS method by coupling the goal ( $\mathrm{i}^{*}$-method) and scenario (UML diagram) and added viewpoints (Preview) to describe non-functional requirements for the elicitation of requirements for a cooperative information system. But this method does not explicitly describes the relations between the actors and did not include the concept of activities (group of actions) and team which are important in a cooperative information system.

\subsection{Tropos-i* method}

Tropos [5], which is requirements-driven in the sense that it is based on concepts used during early requirements analysis. To this end, we adopt the concepts offered by i* [21], a modeling framework offering concepts such as actor, agent, position and role, as well as social dependencies among actors, including goal, softgoal, task and resource ones. These concepts are used to model not just early requirements for a system, but also late requirements, architectural design and detailed design. The methodology spans four phases of software development:

- Early requirements, concerned with the understanding of a problem by studying an existing organizational setting; the output of this phase is a an organizational model which includes relevant actors and their respective goals;

- Late requirements, where the system-to-be is described within its operational environment, along with relevant functions and qualities;

- Architectural design, where the systems global architecture is defined in terms of subsystems, interconnected through data and control flows;

- Detailed design, where each architectural component is defined in further detail in terms of inputs, outputs, control, and other relevant information.

Goal modeling like Tropos-i* is an effective way to identify requirements. The argument of goal driven approaches is that the rationale for developing a system is to be found outside the system itself, in the enterprise in which the system shall function.

But it is difficult for domain experts to deal with the fuzzy concept of a goal. Yet, domain experts need to discover the goals of real systems. It is often assumed that systems are constructed with some goals in mind. However, goals are not given and therefore the question as to where they originate from acquires importance.

-The goal process do not reflect the actual situation but an idealized environmental one. Therefore, proceeding from this may lead to ineffective requirements. Thus, goal discovery is rarely an easy task. Add to this The method does not highlights the teams (group of actors) and their descriptions or descriptions of the activities and actions of a system that we need to find a CIS.

\subsection{VORD method}

VORD [10] was developed at the University Lancasteret proposed by Sommerville and Kotonya (1996). It is a method for pre-validation of specifications, mainly dedicated to interactive systems and resolution of viewpoints. VORD introduced viewpoints focused on user issues and organizational concerns. The model adopted for the viewpoints is service oriented; viewpoints play an analogous role to clients in a client-server system.

A viewpoint VORD encapsulates a set of attributes that help define and structure specifications. Briefly, a viewpoint template includes the following components: Identifier, Label, Type, Attributes, Requirements, Event scenarios.

The VORD method is useful in the detection of user needs, and also in identifying services that the user expects the sys- 
tem. It provides a structured method for the collection, documentation, analysis, and specification of viewpoints and needs. The views are used to describe the different system users.

- However VORD method does not explicitly support the analysis of interactions between and within all viewpoints, it is oriented service, and does not represent the cooperation between actors, or the activities descriptions and actions of the system, we don't find the notion of team which is important in a CIS.

- The viewpoints in VORD are predefined and rigid, it is not flexible and do not let the opportunity for developers to use their own notations and does not support changing requirements.

\subsection{VOSE method}

ViewPoint Oriented System Engineering, VOSE, was developed to "Imperial College" in London in the early 90s by Finkelstein, Nuseibeh et al. (1992) as a framework for the integration of development methods in compound systems (composite systems). These are systems that require the combination of different technologies and require the work of experts in various fields of application, each with its own interest in the system.

Each viewpoint is defined as an actor (or role in the context of system development) and his viewpoints on the system, represented by its partial knowledge of the system (responsibility). This information is organized in a viewpoint and represented by a scheme of five dimensions: style, domain, specification, work plan, and work record.

This method can well describe the requirements of composite systems but is not suited to cooperative information systems because it does not allow to define sets of interaction and cooperation between actors and we don't find the notion of team which is important in a CIS.

- As in VORD, the viewpoints in VOSE are predefined and rigid, it is not flexible and do not let the opportunity for developers to use their own notations.

The problem which we have found with these more structured approaches (VOSE, VORD, MAMIE) is that they are too rigid. They are based around the idea of a single type of viewpoint and require the specification to be fitted around this concept, this is why we propose our approach VpCIS which is flexible and explicit defining actors, interaction between the actors, teams, activities and actions of the system, it let the developers and the users to define their needs and requirements using the representation style they want.

\section{VpCIS approach}

To minimize the disadvantage identified above, we propose a method based on an approach with 5 dimensions that integrates viewpoints from the needs analysis phase as shown in figure 1 to describe the needs of a CIS, these viewpoints will allow us to describe the actors, interaction between them, activities and actions, notions that we have find in a CIS. (an action is accomplished by an actor, an activity is a group of actions assigned to a group of actors that have to work together to accomplish it).

The figure 1 describes the following basic concepts:

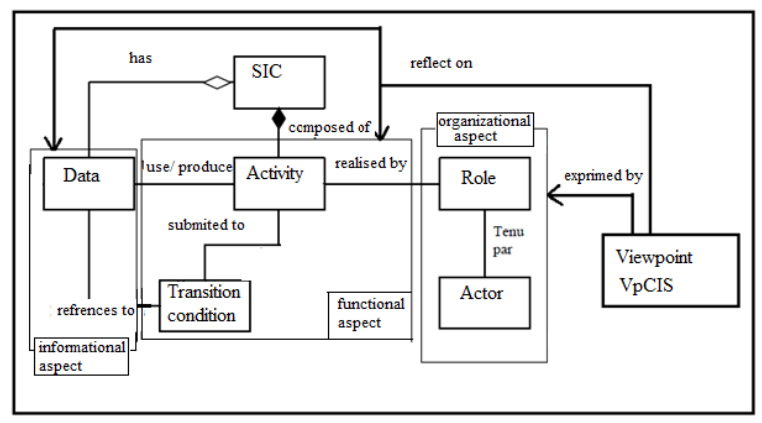

\section{Figure 1. CIS meta-model integrating view- points}

\section{Organizational aspect:}

-Organizational role : it is the list of attributes, skills and expertise of a CIS actor(participant). This role defines the position of the actor in an organization.

-Actor : also called "agent", "participant" or "user", the actor is an entity (person), a member of an organization responsible for carrying out the activities entrusted, through its roles.

\section{Functional aspect:}

-Activity : an activity is a step in a process in which an elementary action (ie non-decomposable) is executed.

-Transition condition : it is the criterion that is necessary to satisfy to change the status of an activity, or to move to the next activity; it is expressed in the form of event or logical expression.

\section{Informational aspect:}

-Relevant data : this is the object that is manipulated during the execution of an activity; the data can be used as input may also be generated by the action.

In what follows we present our approach VpCIS which consists at modeling level M2 in a language of viewpoint for a CIS: a viewpoint meta-model to describe these aspects of a CIS, this meta-model aims to describe an actor and a group of actors (team) using the viewpoints associated to five dimensions: process, level of modeling, level of description, domain and expression mode, that will allow us to describe the actor and his interactions with other actors and his activities and actions. This meta-model will help us to instantiate viewpoints actors and group of actors (team) 
at M1 modeling level and use these viewpoints at M0 level to describe a CIS in the real world.

Add to this, we use as a mode of representation of the CIS the use case diagram, an UML diagram as UML provides tools to describe the different phases of development. The use case diagram lets us to highlight the actors, interactions between them, the activities and actions, and to deduce two types of actors and actions in the meta-model: primary(intervene directly in the CIS) and secondary (intervene indirectly in the CIS).

The following figure 2 represents the integration of the meta-model VpCIS in the meta-model CIS.

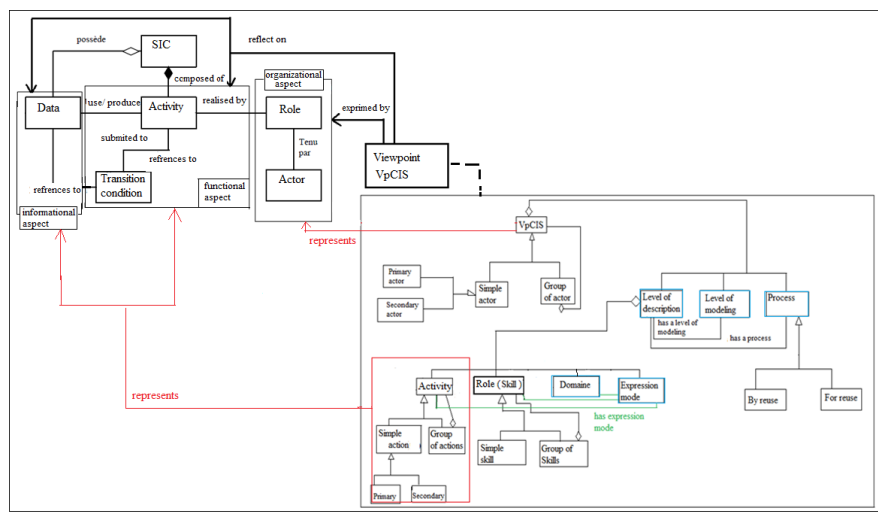

Figure 2. CIS meta-model integrating VpCIS meta-model

A viewpoint VpCIs meta-model in the M2 level can be a simple actor or a group of actors as shown in Figure 2, it is composed of the following:

1. Process: the construction process can be by or for reuse. We have a set of information systems that want to cooperate in order to have a cooperative information system. To describe a CIS we can reuse actors and activities already defined in different cooperating systems or we can have to define new actors and activities.

2. Level modeling: the viewpoint $\mathrm{VpCIs}$ may intervene in one of the three layers of the architecture modeling:

- M2, the meta-models such as UML;

- M1, the models such as the class diagram;

- M0, the real world (case study);

This will allow us to describe the different categories of actors involved in each level modeling.

3. Level of description: this level comprises the following:

- Activity: may be a single action or group of actions to be done by an actor or group of actors.

- Skill: can be a skill of single actor or a group of skills of a group of actors.
- 4. Domain: could be a generic domain or an application domain:

- Generic domain: in our case it is therefore the CIS, using the viewpoints we describe the actors and activities involved in modeling level M2 and M1 (expert, designer CIS ...)

- Application domain: using also the VPs we describe the actors and activity level M0 (actors and activities of the case study)

- 5. Expression mode: representation mode of activities, skills and domain, the user can choose the expression mode that he wants to describe his needs.

The viewpoint VpCIs simple actor and group of actors (team) and their attributes are described at M1level modeling.

We pass now to M1 level, where we instantiate the viewpoint actor and group of actors (team) from the meta-model of level M2 using the 5 dimensions:

The viewpoint group of actors (team) has the following attributes:

\section{- Process}

- Level modeling

- Level of description:

- Name

- Goal

- Skills:

* Expression mode of the group of skills

* Skills

- Domain:

* Expression mode of the domain

* Domain

- Activity (Group of actions):

* Expression mode of the activity

* Group of actions

* Interaction between the actors:

- Inter link

- Intra link

* Required data

* Constraints on data

* Output data

$*$ history

These attributes are detailed in the following table 1:

The viewpoint simple actor has the following attributes: 
Table 1. Viewpoint Group of actors

\begin{tabular}{|c|c|}
\hline Attributes & Description \\
\hline Process & $\begin{array}{l}\text { If the group of actors defines new actors } \\
\text { the process is for reuse; if it uses actors } \\
\text { already defined the process is by reuse }\end{array}$ \\
\hline $\begin{array}{l}\text { Level } \\
\text { modeling }\end{array}$ & $\begin{array}{l}\text { Level modeling where the group of actors } \\
\text { intervenes }\end{array}$ \\
\hline Name & Name of the group of actors. \\
\hline Goal & What have to do the group of actors. \\
\hline $\begin{array}{l}\text { Expression } \\
\text { mode of } \\
\text { the group } \\
\text { of skills }\end{array}$ & $\begin{array}{l}\text { Representation mode of the skills group } \\
\text { of the actors like an activity diagram or } \\
\text { textual. }\end{array}$ \\
\hline $\begin{array}{l}\text { Group of } \\
\text { Skills }\end{array}$ & Description of the skills set of the actors \\
\hline $\begin{array}{l}\text { Expression } \\
\text { mode of } \\
\text { the domain }\end{array}$ & $\begin{array}{l}\text { Representation mode of the domain } \\
\text { of the group of actors }\end{array}$ \\
\hline Domain & $\begin{array}{l}\text { Description of the domain of the } \\
\text { group of actors }\end{array}$ \\
\hline $\begin{array}{l}\text { Activity } \\
\text { (group of } \\
\text { actions) }\end{array}$ & $\begin{array}{l}\text { Name of the activity that is assigned to } \\
\text { the group of actors }\end{array}$ \\
\hline $\begin{array}{l}\text { Expression } \\
\text { mode of } \\
\text { the activity } \\
\text { (the group } \\
\text { of actions) }\end{array}$ & $\begin{array}{l}\text { Representation mode of the group of } \\
\text { actions }\end{array}$ \\
\hline $\begin{array}{l}\text { Group of } \\
\text { actions }\end{array}$ & $\begin{array}{l}\text { Sets of actions of each actor who } \\
\text { intervenes in the execution of the activity }\end{array}$ \\
\hline $\begin{array}{l}\text { Interaction } \\
\text { between } \\
\text { the actors }\end{array}$ & Inter link or intra link \\
\hline Intra link & $\begin{array}{l}\text { The actor has links with other actors } \\
\text { from the same group of actors }\end{array}$ \\
\hline Inter Link & $\begin{array}{l}\text { The actor has links with other external } \\
\text { actors from other groups of actors. }\end{array}$ \\
\hline $\begin{array}{l}\text { Required data: } \\
\text { (functional } \\
\text { requirements) }\end{array}$ & $\begin{array}{l}\text { Requirement that can have the actor } \\
\text { and information needed to accomplish } \\
\text { the activity }\end{array}$ \\
\hline $\begin{array}{l}\text { Constraints } \\
\text { on data: } \\
\text { non-functional } \\
\text { requirements }\end{array}$ & $\begin{array}{l}\text { non-functional requirements that can have } \\
\text { the actor. }\end{array}$ \\
\hline Provided data & $\begin{array}{l}\text { output information provided from the VP } \\
\text { accomplishing his goal. }\end{array}$ \\
\hline History & When start the activity and when finish. \\
\hline
\end{tabular}

\section{- Process}

\section{- Level modeling}

\section{- Level of description:}

- Type

- Name

- Goal

- Skill:

* Expression mode of the actor skill

* Skill

- Domain:

* Expression mode of the domain

* Domain

- Action:

* Activity (group of actions)

* Expression mode of the action

* Action (description of the action)

* Interaction between the actors:

- Inter link

- Intra link

* Required data

* Constraints on data

* Output data

* history

These attributes are detailed in the following table 2:

\section{Conclusion}

In this article we discussed our motivation for the use of viewpoints in the requirement engineering phase of a CIS, We proposed after the VpCIS approach which define a meta-model of viewpoints in the M2 level modeling for the needs analysis phase of a CIS, to decompose the system's needs and simplify the CIS's modeling. We instantiated after that the necessary viewpoints to describe these needs and requirements in the M1 level modeling from the meta-model. We expect to develop a tool which allows to support this approach and develop a CIS.

\section{References}

[1] International standard iso/iec/ieee 42010, systems and software engineering architecture description. Systems and software engineering Architecture description, 2011.

[2] B. Aubert and A. Dussart. Systemes d'information interorganisationnels. Rapport Bourgogne, CIRANO, 2002.

[3] H. Bendjenna. Ingenierie des exigences pour les processus inter-organisationnels. $\mathrm{PhD}$ thesis, University of Constantine and Toulouse, Algeria, France, 2010. 


\section{Table 2. Viewpoint Simple actor}

\begin{tabular}{|c|c|}
\hline Attributes & Description \\
\hline Process & $\begin{array}{l}\text { If we define a new actor the process is for } \\
\text { reuse; if it is already defined the process } \\
\text { is by reuse }\end{array}$ \\
\hline $\begin{array}{l}\text { Level } \\
\text { modeling }\end{array}$ & Level modeling where the actor intervenes \\
\hline Type & Primary or Secondary \\
\hline Name & Name of the actor \\
\hline Goal & What have to do the actor \\
\hline $\begin{array}{l}\text { Expression } \\
\text { mode of } \\
\text { the skill }\end{array}$ & $\begin{array}{l}\text { Representation mode of the actor skill like } \\
\text { an activity diagram or textual }\end{array}$ \\
\hline Skill & Description of the actor skill \\
\hline $\begin{array}{l}\text { Expression } \\
\text { mode of } \\
\text { the domain }\end{array}$ & Representation mode of the actor domain \\
\hline Domain & Description of the actor domain \\
\hline Action & Name of the actor action \\
\hline $\begin{array}{l}\text { Activity } \\
\text { (group of } \\
\text { actions) }\end{array}$ & $\begin{array}{l}\text { Name of the Activity that is assigned to } \\
\text { the actor }\end{array}$ \\
\hline $\begin{array}{l}\text { Expression } \\
\text { mode of } \\
\text { the action }\end{array}$ & Representation mode of the actor action \\
\hline Action & Description of the actor action \\
\hline $\begin{array}{l}\text { Interaction } \\
\text { between } \\
\text { the actors }\end{array}$ & Inter link or intra link \\
\hline Intra link & $\begin{array}{l}\text { The actor has links with other actors } \\
\text { from the same organization where he works. }\end{array}$ \\
\hline Inter Link & $\begin{array}{l}\text { The actor has links with other external } \\
\text { actors from other organizations. }\end{array}$ \\
\hline $\begin{array}{l}\text { Required data: } \\
\text { (functional } \\
\text { requirements) }\end{array}$ & $\begin{array}{l}\text { Requirement that can have the actor } \\
\text { and information needed to accomplish } \\
\text { his action }\end{array}$ \\
\hline $\begin{array}{l}\text { Constraints } \\
\text { on data: } \\
\text { non-functional } \\
\text { requirements }\end{array}$ & $\begin{array}{l}\text { non-functional requirements that can have } \\
\text { the actor. }\end{array}$ \\
\hline Provided data & $\begin{array}{l}\text { output information provided from the VP } \\
\text { accomplishing his goal. }\end{array}$ \\
\hline History & When start the action and when finish. \\
\hline
\end{tabular}

University of Sydney and Toulouse, Toulouse, France, 2007.

[7] M. Faisal and M. Hussain. Emphasizing requirement elicitation process for electronic payment secured system using vord methodology-a practical approach. International Journal of Computer Science and Information Technologies, 2012.

[8] A. Finkelsetin, B. J.Kramer, L. Nuseibeh, and M. Finkelstein. Viewpoints: A framework for integrating multiple perspectives in system development. International Journal of Software Engineering and Knowledge Engineering, 1992.

[9] E. Hull, K. Jackson, and J. Dick. Requirements engineering. Springer, 2010.

[10] G. Kotonya and I. Sommerville. Requirements engineering : Process and techniques. John Wiley and Son, Great Britain, 1998.

[11] S. Mehrdad, A. Finkelsetin, and G. Michael. Viewpoints. In encyclopedia of software engineering. P. Laplante, New York, 2010. Taylor and Francis.

[12] J. Monateri and M. Sapina. Dynamique des relations entre entreprises, strategies manufacturieres et arrangements contractuels durables. 3rd Congres international de genie industriel, 1999.

[13] G. Mullery. Core: a method for controlled requirements specification. In The 4th international conference on software engineering, Munich, 1979. IEEE Computer Society Press.

[14] J. Mylopoulos. Conceptual modelling iii. structured analysis and design technique(sadt). Web, 2004.

[15] C. Rolland, C. Souveyet, and C. Ben Achour. Guiding goal modelling using scenarios. IEEE Transactions on Software Engineering, Special Issue on Scenario Management, 1998.

[16] D. Ross and K. Schoman. Structured analysis for requirements definition. IEEE Transactions on Software Engineering, 1977.

[17] A. Salem. Requirements analysis through viewpoints oriented requirements model (vord). International Journal of Advanced Computer Science and Applications, 2010.

[18] I. Sommerville and P. Sawyer. Viewpoints: Principles, problems and a practical approach to requirements engineering. Annals of Software Engineering, 1997.

[19] I. Sommerville, P. Sawyer, and S. Viller. Viewpoints for requirements elicitation: a practical approach. IEEE International Conference on Requirements Engineering, 1998.

[20] J. TOUZI. Aide e la conception de Systeme d'Information Collaboratif support de l'interoperabilite des entreprises. $\mathrm{PhD}$ thesis, TOULOUSE, France, 2007.

[21] E. Yu. Modelling Strategic Relationships for Process Reengineering. $\mathrm{PhD}$ thesis, Toronto, canada, 1995.
[4] H. Bendjenna, N. Zarour, and P. Charrel. Mamie: a methodology to elicit requirements in inter-company co-operative information systems. CIMCA, 2008.

[5] J. Castro, P. Giorgini, M. Kolp, and J. Mylopoulos. Tropos: A requirements-driven methodology for agent-oriented software. 2004.

[6] C. R. Coulin. A Situational Approach and Intelligent Tool for Collaborative Requirements Elicitation. PhD thesis, 